\title{
Effects of hunger and thirst levels during sugar and sugar-saccharin consumption on later preferences
}

PATRICK J. CAPRETTA MIAMI UNIVERSITY

Sixteen mature male rats first received six daily $30 \mathrm{~min}$ tests to determine which of two solutions $110 \%$ sucrose or $10 \%$ sucrose $+0.1 \%$ saccharin) was preferred. Each $S$ was then allowed to drink its nonpreferred solution before maintenance feedings on one day and its preferred solution after feedings on another day for 10 days of alternating $30 \mathrm{~min}$ trials. Posttests given on the five days following training failed to show any reliable changes in preferences. Such results suggest that a nonaversive training procedure is ineffective in changing the preference value of highly palatable foods.

Revusky (1967) found that the preference for a food (grape juice) was greater if his rats had previously consumed it when hungry than when satiated regardless of the test deprivation schedule. In the present research, a different food was used in a similar design to test the generality of Revusky's conclusions.

Method

The Ss were 16 male Aberdeen-Wistar rats, 130 days old at the start of the experiment. The experimentally naive Ss were handled and habituated to drink plain water in their training and testing cages before the actual study began. The metal cages each measured $\begin{array}{lllllll}7 & \times & 7 & \times & 7 & \text { in. and contained two } 100 \mathrm{ml}\end{array}$ water bottles with glass nondrip drinking spouts placed about 3 in. apart. Two test solutions, $10 \%$ sugar (10 g of sucrose in $90 \mathrm{ml}$ of tap water) and $10 \%$ sugar plus $0.1 \%$ sodium saccharin were given to the $\mathrm{Ss}$ in ad lib quantities under $22 \mathrm{~h}$ food and $12 \mathrm{~h}$ water deprivation for six consecutive days of pretraining preference tests lasting $30 \mathrm{~min}$ each. The test bottles were changed from right to left on successive days. After two days of ad lib feeding in their home cages, 11 experimental Ss were given access to their preferred solution (that which $S$ had drunk more of, on the average, during pretraining tests) immediately after they were fed, and their nonpreferred solution just before they were fed (i.e., $22 \mathrm{~h}$ hungry and $12 \mathrm{~h}$ thirsty). The remaining five control Ss received their preferred and nonpreferred solutions just after feedings. Thus, each $\mathrm{S}$ experienced $1030 \mathrm{~min}$ trials, one each day, with a single solution under either the same or alternating need states. A final series of posttraining preference tests were given two days following the end of training. Each $\mathrm{S}, 22 \mathrm{~h}$ hungry and $12 \mathrm{~h}$ thirsty, received the two solutions in an alternated right-left position for a $30 \mathrm{~min}$ period once a day for five consecutive days. The Ss were weighed before and after the study.

Results

The proportion of sugar to sugar-saccharin solution consumed by each $S$ during pre- and posttesting is given in Table 1. Pretest data show that 12 rats (eight experimental and four control) drank more sugar-saccharin than sugar solution, while the remaining four (three experimental and one control) preferred the plain sugar water to varying degrees. Following training, all of the eight experimental rats given the sugar solution under conditions of hunger and thirst (Ss 1-8) increased their intake of sugarsaccharin relative to the sugar solution. Slight shifts in preference toward the reinforced solution are ap-

Table 1. Amount of $10 \%$ Sucrose Solution Consumed Divided by the Total Amount of Test Solution Consumed for All Subjects

\begin{tabular}{llllll}
\hline S & Pretest & Posttest & S & Pretest & Posttest \\
\hline 1 & $.49(108) \mathrm{S}^{*}$ & $.19(133)$ & 9 & $.79(140) \mathrm{SS}$ & $.57(158)$ \\
2 & $.22(113) \mathrm{S}$ & $.13(121)$ & 10 & $.69(100) \mathrm{SS}$ & $.61(108)$ \\
3 & $.49(150) \mathrm{S}$ & $.11(160)$ & 11 & $.70(128) \mathrm{SS}$ & $.73(164)$ \\
4 & $.31(126) \mathrm{S}$ & $.26(156)$ & 12 & $.12(190) \mathrm{C}$ & $.31(200)$ \\
5 & $.36(154) \mathrm{S}$ & $.21(141)$ & 13 & $.88(124) \mathrm{C}$ & $.69(176)$ \\
6 & $.36(139) \mathrm{S}$ & $.07(136)$ & 14 & $.29(102) \mathrm{C}$ & $.23(137)$ \\
7 & $.34(122) \mathrm{S}$ & $.28(118)$ & 15 & $.33(140) \mathrm{C}$ & $.29(156)$ \\
8 & $.32(156) \mathrm{S}$ & $.29(182)$ & 16 & $.37(153) \mathrm{C}$ & $.15(114)$ \\
\hline
\end{tabular}

*Numbers in parentheses refer to the total amount of test solution consumed (rounded to the nearest $\mathrm{ml}$ ). S (sucrose), SS (sucrose-saccharin), or $\mathrm{C}$ (neither) indicates which solution was given under conditions of hunger and thirst during training, i. e., reinforced. 
parent in the data for two (Ss 9 and 10) of the three rats that preferred the sugar solution in pretesting. Proportions for the remaining experimental animal (S 11) were virtually unchanged from pre- to posttesting. Of the controls, only one of the rats (S 12) went against the general trend towards greater acceptance of the sugar-saccharin solution.

Consumption during training was higher when the animals were hungry and thirsty $(M=27 \mathrm{ml})$ than when they were satiated $(M=18 \mathrm{ml})$. There were no major fluctuations in the body weights of any of the rats between the start and completion of the study.

\section{Conclusions}

Reinforcement of the nonpreferred solution by allowing it to be consumed under a state of hunger and thirst appeared in this experiment to have little, if any, effect in enhancing its relative palatability. More important than any training effect was the general trend in all animals toward a greater acceptance of the sweeter sugar-saccharin solution. These results are consistent with earlier evidence (Braveman, 1965) that nonaversive means of changing the preference values of highly palatable sugar and saccharin solutions are relatively ineffective compared to certain aversive conditioning procedures (Braveman \&
Capretta, 1965; Capretta, 1961; Dietz \& Capretta, 1966). Revusky's research (1967), on the other hand, suggests that such a nonaversive procedure as used in this study is effective in altering the preference value of foods of lower palatability to rats.

References

BRAVEMAN, N. The relative effectiveness of four experimental techniques for the modification of food preferences in rats. Unpublished master's thesis, Miami University, 1965.

BRAVEMAN, N., \& CAPRETTA, P. J. The relative effectiveness of two experimental techniques for the modification of food preferences in rats. In, Proc. 73rd annu. conv. Amer. Psychol. Assoc. 1965, 1, 129-130

CAPRETTA, P. J. An experimental modification of food preferences in chickens. J. comp. physiol Psychol, 1961, 54, 238-242.

DIETZ, M. N., \& CAPRETTA, P. J. Modification of sugar and sugar saccharin preferences in rats as a function of electric shock to the mouth. In, Proc. 74th annu. conv. Amer. Psychol. Assoc., 1966, 1, 161-162.

REVUSKY, S. H. Hunger level during food consumption: effects on subsequent preference. Psychon. Sci, 1967, 7, 109-110. Note

1. This study was conducted at the University of Aberdeen (Scotland) where the author was an NIMH Special Postdoctoral Fellow, 1966-67, under the helpful sponsorship of John J. Cowley of the Department of Psychology. 